\title{
Perioperative Lung Protective Strategies
}

\author{
Marc J Licker ${ }^{1 *}$, Jean-Marie Tschopp ${ }^{2}$ and John Diaper ${ }^{1}$ \\ ${ }^{1}$ Department of Anesthesiology, Pharmacology and Intensive Care, University Hospital of Geneva, rue Gabrielle-Perret-Gentil, CH-1205 Geneva, Switzerland
} ${ }^{2}$ Department of Internal Medicine, Reseau Valais Santé, CH-1950 Sion

\begin{abstract}
The traditional intraoperative ventilatory settings (tidal volume $>10 \mathrm{ml} / \mathrm{kg}$ ideal body weight) can be harmful even in patients with healthy lungs. In the operating theatre, safe anesthesia and optimization of oxygen delivery should be achieved while minimizing the deleterious effects of surgical trauma and avoiding iatrogenic complications. This review examines the mechanisms of perioperative lung injuries and particularly the injurious effects of mechanical ventilation. Protective lung strategies are discussed using a physiological approach, being mainly focused on the surgical patients with "healthy" lungs.
\end{abstract}

\section{Introduction}

Currently, the incidence of postoperative pulmonary complications (PPC) far outnumbers cardiovascular complications [1]. They vary from $10 \%$ to $70 \%$, depending on their definition, study design (retrospective or prospective), the heterogeneity of patient populations and the type of procedure [2]. In thoracic surgery, the main causes of perioperative deaths have now shifted from cardiovascular to infectious and pulmonary complications [3,4]. Pulmonary morbidity has also been associated with increasing health care costs and poor outcome as reflected by prolonged hospital stay, (re-)admission in intensive care units and reduced long-term survival $[5,6]$.

Transient and self-limiting impairments in gas exchange should be considered as part of the anesthesia emergence period and as the physiological response to surgery. Most of the patients undergoing cardiothoracic or abdominal operations present some degree of hypoxemia and diffuse micro-atelectasis that will barely impact on the postoperative clinical course. In contrast, pleural effusions, sustained bronchospasm, lobar atelectasis or hypoxemia unresponsive to supplemental oxygen may forecast serious adverse events such as bronchopleural fistula, pneumonia, acute lung injury (ALI) or respiratory failure [7].

Predictive factors of PPCs include patient-related factors (e.g., chronic obstructive pulmonary disease [COPD], advanced age, poor nutritional status, decreased exercise tolerance, heart failure) and intraoperative related factors (i.e., emergency surgery, upper abdominal and intra-thoracic procedures, duration of anesthesia, presence of a nasogastric tube, ventilatory settings, fluid balance) [2,8]. These procedure-related factors are much more amenable to modification than preexisting chronic diseases.

In an effort to standardize the reporting of adverse perioperative events, Dindo and coll. [9] have validated a 5-grade scoring system based on the therapeutic consequences and residual disabilities in relation to surgical operations. Grade I complications entail any deviation from the normal postoperative course with no need for medical interventions (except a slight increase in inspiratory oxygen fraction $\left[\mathrm{FIO}_{2}\right]$ or lung recruitment maneuvers). Grades II and III complications require non-invasive ventilatory support, pharmacological treatment (e.g., bronchodilators, diuretics) or specific interventions (e.g., fiberoptic bronchoscopy, thoracic drainage). Grade IV includes life-threatening complications (single-or multiple organ failure) requiring ICU admission and/or mechanical ventilation.

\section{Mechanisms of Perioperative Pulmonary Injuries}

\section{Atelectasis}

Collapsed lung areas or atelectasis develop in about $90 \%$ anaesthetized patients, irrespective of ventilatory control (spontaneous or mechanically supported) and of anesthesia type (intravenous agent, volatile anaesthetics or, combined general anesthesia and regional block) [10]. Atelectasis formation predominantly results from the reduction of lung volumes and from deficient or abnormal synthesis of surfactants that occur during anesthesia and could persist or even worsen after completion of the surgical procedure.

By changing from upright to supine position, the functional respiratory capacity (FRC) is decreased by $0.8-1.0 \mathrm{~L}$ and a further reduction of 0.4-0.5 L occurs after the induction of anesthesia owing to the relaxation of the respiratory muscles and the decrease in thoracic elastic recoil $[11,12]$. Ventilation with enriched oxygen mixture $\left(\mathrm{FIO}_{2}\right.$ $>80 \%$ ) promotes the development of atelectasis as a result of complete absorption of $\mathrm{O}_{2}$ in poorly ventilated lung regions. Depending on the duration of mechanical ventilation, $3 \%$ to $40 \%$ of the total lung volume collapses in the dependent zone resulting in impaired gas exchange intraoperatively [13]. Moreover, atelectasis impairs the clearing of bronchial secretions, it impedes lymphatic flow and may become a focus of infection in the postoperative period.

In obese patients, the healthy lungs are compressed by the "heavy" weight of the chest/abdominal wall, resulting in further aggravation of the restrictive pulmonary syndrome associated with anesthesia and surgery. Likewise, in acute lung diseases and heart failure, ongoing inflammation and fluid accumulation within the lung interstitium and the alveolar space, tissue tend to expel air/gas out of the alveoli and thereby promote the development of atelectasis.

\section{Ventilator-induced lung injuries (VILI)}

During spontaneous ventilation (at rest), tidal volume $\left(\mathrm{V}_{\mathrm{T}}\right)$ and transpulmonary pressure (Ptp) in healthy subjects vary within tight limits of 4 to $6 \mathrm{ml}$ per $\mathrm{kg}$ of ideal body weight (IBW) and 4 to $8 \mathrm{mmHg}$, respectively.

Surprisingly and for decades, anaesthetists have been taught to apply "unphysiological" large tidal volume (10 to $15 \mathrm{ml} / \mathrm{kg}$ ) to prevent the development of atelectasis.

*Corresponding author: Marc J Licker MD, Department of Anesthesiology, Pharmacology and Intensive Care, University Hospital of Geneva, rue GabriellePerret-Gentil, CH-1205 Geneva, Switzerland, E-mail: Marc-joseph.licker@hcuge.ch

Received November 11, 2011; Accepted December 19, 2011; Published January 12, 2012

Citation: Licker MJ, Tschopp J, Diaper J (2012) Perioperative Lung Protective Strategies. J Pulmonar Respirat Med S2:002. doi:10.4172/2161-105X.S2-002

Copyright: @ 2012 Licker MJ, et al. This is an open-access article distributed under the terms of the Creative Commons Attribution License, which permits unrestricted use, distribution, and reproduction in any medium, provided the original author and source are credited. 
Mechanical inflation of "physiological" low $\mathrm{V}_{\mathrm{T}}(4-8 \mathrm{ml} / \mathrm{kg})$ produces higher Ptp and may cause subtle lung injuries over several hours: neutrophil infiltration, rupture of alveolar-bronchial attachment and chondroitin-sulfate proteoglycan fragmentation in the extracellular matrix (ECM) [14]. When a larger $\mathrm{V}_{\mathrm{T}}$ is delivered (with or without increased Ptp) over a prolonged time period, auto regulatory local responses are triggered in an attempt to maintain low pulmonary compliance while protecting the ECM against fluid overload (e.g., further macro-molecular fragmentation, activation of matrix metalloprotease and up regulation of collagen synthesis in the ECM) [15-17]. In addition, the cyclic stretch and hyperoxic exposure of lung epithelial and endothelial cells have been shown to trigger the formation of reactive oxygen/nitrogen intermediates (ROIs/RNs) and to induce various patterns of cell death (necrosis and apoptosis) resulting in alteration in the alveolar-capillary barrier [18-20]. An up regulation of pro-inflammatory mediators (TNF- $\alpha$ and interleukin-8) associated with diffuse alveolo-capillary lesions has also been demonstrated in rabbits ventilated with large $\mathrm{V}_{\mathrm{T}}$ under moderate hyperoxia (compared with normoxia/large $\mathrm{V}_{\mathrm{T}}$ and hyperoxia/normal $\mathrm{V}_{\mathrm{T}}$ ) [21,22].

Mechanical ventilation induces alveolar injuries by repetitive opening and closing of unstable lung units due to the inactivation of surfactant and the excessive mechanical stress between atelelectatic areas and neighbouring areas with low ventilation/perfusion ratio $[23,24]$.

With the pioneering experimental work of Dreyfuss et al. [25], ICU physicians first became aware of the potential deleterious effects of positive pressure ventilation [23]. Several reports suggested that the application of high $\mathrm{V}_{\mathrm{T}}(>8 \mathrm{ml} / \mathrm{kg})$, high plateau inspiratory pressure and/or high inspiratory $\mathrm{FIO}_{2}(100 \%)$ in critically-ill patients (without ALI) may produce pulmonary changes mimicking ALI as expressed by diffuse alveolar damage, recruitment of inflammatory cells and production of pro-inflammatory mediators [25].

In anesthetized patients with healthy lungs, - besides "high" $\mathrm{V}_{\mathrm{T}}$ and elevated inspiratory pressure -, other risk factors for lung injuries have been identified [26-29]. Fluid over hydration increases capillary hydrostatic pressure and promotes interstitial/alveolar edema particularly when lymphatics are disrupted. Additionally, tissue trauma, ischemia-reperfusion, blood transfusion and exposure to extracorporeal devices may all concur to trigger a widespread inflammatory response with potential deleterious effects on the lungs [30].

Some individuals are prone to develop ALI, given their deficient lung defence and repair mechanisms (e.g., antioxidant, heat shock protein, p75 receptor for tumour necrosis factor alpha [TNF- $\alpha$ ]) that fail to counteract the inflammatory and oxidative responses to damaging insults [31]. Genetic disruption of the transcription factor Nrf2 (NF-E2 related factor 2) has been associated with overexpression of proinflammatory cytokines and increased risk of ALI due to hyperoxia and high $\mathrm{V}_{\mathrm{T}}$. Relevant gene variants or single nucleotide polymorphisms (SNPs) in ALI candidate genes have been tested for differences in allelic frequency in cohort studies [32]. The Nrf2617 SNP (A/ or C/A allele) has been associated with a greater risk of post-trauma ALI relative to subjects bearing the wild type. Likewise, in patients undergoing oesophagectomy, SNP of the angiotensinconverting enzyme (D/D genotype) has been found to be highly predictive of major pulmonary complications [33].

Over the last two decades, - in thoracic surgery requiring onelung ventilation (OLV) -, the routine settings for $\mathrm{V}_{\mathrm{T}}$ have been shifted downwards (from 10 to $12 \mathrm{ml} / \mathrm{kg}$ to $6-9 \mathrm{ml} / \mathrm{kg}$ ) given the growing body of scientific knowledge demonstrating the injurious effects of large $\mathrm{V}_{\mathrm{T}}$ [30].

\section{Perioperative Lung Protective Strategies}

\section{Volatile anesthetics}

Compared with intravenous hypnotics, volatile anaesthetics induce bronchodilatation and may inhibit the hypoxic pulmonary vasoconstriction (HPV) although no significant difference has been reported regarding blood oxygenation when anaesthetic administration is titrated to achieve a similar depth of anesthesia [34].

Based on experimental models of lung ischemia-reperfusion (I-R) and lipopolysacharide (LPS) or zymosan injuries, volatile anaesthetics such as isoflurane and sevoflurane have demonstrated potent immunomodulatory properties $[35,36]$. In isolated rat lungs subjected to LPS challenge or I-R, pre-treatment with volatile anesthetics has been shown to attenuate lung edema and microvascular protein leakage as a result of a reduction in polymorphonuclear recruitment, decreased cytokine release from alveolar macrophages/monocytes as well as attenuation of the overproduction of pro-inflammatory mediators and nitric oxide. Besides multiorgan preconditioning effects, both isoflurane and sevoflurane also exert post conditioning effects as far as they are administered within 1-2 hours of the onset of LPS-induced ALI. Noteworthy, the concomitant administration of beta-blockers counteract the anti-inflammatory effects of volatile anaesthetics [37].

Preliminary data obtained in patients undergoing thoracic surgery lend support to the anti-inflammatory effects of volatile anaesthetics, compared with propofol. Schilling and coll reported an attenuate release of IL-8, IL-10, elastase TNF- $\alpha$ and soluble intercellular adhesion molecule type 1 in the bronchoalveolar lavage (BAL) of patients anesthetized with desflurane (vs propofol, $\mathrm{n}=30$ ) [38]. In another RCT, a reduction of inflammatory markers with a trend for fewer respiratory complications was found in patients anesthetized with sevoflurane anesthesia (sevoflurane vs propofol, $\mathrm{n}=40$ ) [39].

\section{Pressure or volume controlled ventilation}

Mechanical ventilation can be classified as either volume controlled (VCV) or pressure controlled (PCV) depending on whether a predetermined $\mathrm{V}_{\mathrm{t}}$ or predetermined peak inspiratory pressure (PIP) is set by the clinician and delivered by the ventilator. Airway resistance as well as resistance and compliance of the respiratory system (ventilator circuit and patient lung and thoraco-abdominal wall) both determine the amount of pressure necessary to deliver the tidal volume and the pattern of pressure-volume loops.

During VCV, inspiratory pressures should be closely monitored to prevent barotrauma whereas during PCV, alarms must be set for inspiratory volumes (low and high) to prevent hypoventilation or hyperventilation. Basically, during VCV, airway pressure increases in response to reduced respiratory compliance, increased airway resistance, or active exhalation and may increase the risk of ventilatorinduced lung injury (if light levels of anesthesia). In contrast, PCV by design, limits the maximum airway pressure delivered to the lung, but may result in variable tidal and minute volume [40,41].

Several manufacturers have incorporated variable flow options as well as volume-targeted, pressure-regulated and time-limited ventilatory modalities in their machines. Accordingly, instead of providing an exact tidal volume each breath, a target volume is set and the ventilator will vary the PIP on a breath to breath basis to achieve that volume. As with PCV, the inspiratory time $\left(\mathrm{T}_{\mathrm{i}}\right)$ limits the length 
of the inspiratory cycle while offering the benefit that the set $V_{t}$ will be achieved with the lowest possible PIP. Pressure regulated modes such as PRVC, Auto-flow (Draeger) or Average Volume Assured Pressure Support (AVAPS) from Philips can most easily be thought of as turning a volume mode into a pressure mode with the added benefit of maintaining more control over $\mathrm{V}_{\mathrm{t}}$ with strictly pressure-control.

Regarding flow characteristics, gas may be delivered by the ventilator as a constant "square" or a "decelerating" wave. The maximal flow in the early part of the inspiratory phase under PCV was initially thought to provide more homogeneous distribution of gas mixture while avoiding alveolar distension and mitigating ventilation-perfusion mismatch [42].

In ALI patients, variations in lung strain have been shown to be minimized by ventilating with PCV compared with VCV, although static mechanics, oxygenation, and hemodynamics remained similar $[43,44]$. Interestingly, the ventilation heterogeneity and patchiness in ventilation during steady-state VCV can be substantially reduced after the transition to PCV [45].

In thoracic surgery, recent interest has been focused on the use of PCV given potential benefits related to the attenuation of lung inflating pressures and the reduction of intrapulmonary shunt. However, conflicting results have been reported regarding the physiological and clinical effects of PCV and VCV. In two studies from Turkey, PCV provided significant reductions in both peak and plateau airway pressures (Ppeak, Ppl) that was associated with better oxygenation than in patients receiving PCV [46,47]. Interestingly, larger benefit was observed in patients with altered pulmonary function while gas exchange was slightly improved when a PEEP of $4 \mathrm{~cm} \mathrm{H}_{2} \mathrm{O}$ was applied. Although other investigators confirmed the lower Ppeak associated with PCV, they failed to replicate the reduction in Ppl neither any benefit in terms of oxygenation [48-51].

Importantly, compared with VCV, although PCV has been shown to produce lower Ppeak within the ventilator circuit, the pressure distal to the tip of the endobronchial tube (bronchus and alveola) was found to be equivalent [52]. Altogether, the current state of knowledge does not provide evidence for superior clinical effects of PCV over VCV in deeply anesthetized/paralyzed patients with healthy lungs receiving full mechanical ventilation.

\section{PEEP}

Following anesthesia induction in the supine position, the FRC decreases and the progressive collapse of various amount of lung areas results in impaired blood oxygenation owing to ventilation-perfusion mismatch $(\mathrm{V} / \mathrm{Q})$.

The addition of PEEP, - by augmenting transpulmonary pressure at each exhalation -, prevents the collapse of the small airways and the fall in FRC, thereby it may minimize the propensity to develop atelectasis [11].

In patients with healthy lung, titrated levels of PEEP has been shown to restore lung volumes and thereby improve lung compliance while decreasing intrapulmonary shunting [53]. Nevertheless, depending on the level of PEEP and the presence of pathological lung conditions, PEEP has the potential to cause both harm and good. PEEP-induced increases in intrathoracic pressure may decrease cardiac output, increase the risk of barotraumas and overdistend normal lung areas, causing additional physiological dead space, particularly in damaged lungs with heterogenous distribution.
In a sheep model of ARDS, comparison of various methods based on pressure-volume curves and gas exchange for setting the optimal PEEP failed to show any significant difference: maximum dynamic compliance, maximum $\mathrm{PaO}_{2} / \mathrm{PaCO}_{2}$, minimum shunt and the lower/ upper inflection points all yielded results that were statistically indistinguishable [54].

In morbidly obese patients, observation of the slope of the $\mathrm{CO}_{2}$ expiratory curve might be helpful to titrate the optimal level of PEEP after a recruitment maneuver [55]. The expiratory volumetric capnography is an easily traced parameter that provides aggregate information about gas exchange at the alveolar-capillary membrane, gas transport within airways, and respiratory mechanics. After a RM, the "best" PEEP is characterized by a flat $\mathrm{CO}_{2}$ slope reflecting facilitated elimination of $\mathrm{CO}_{2}$ as a result of the improved elastic properties of the respiratory system.

In a meta-analysis of eight RCTs involving 330 surgical patients, positive pressure ventilation with PEEP resulted in favourable effects on day 1 postoperatively in terms of higher $\mathrm{PaO}_{2} / \mathrm{FIO}_{2}$ and lesser atelectatic areas, compared with mechanical ventilation without PEEP (or zero-PEEP, ZEEP) [56]. No relevant adverse effects (barotrauma and cardiovascular complications) were reported in the three trials that adequately measured these outcomes. In morbidly obese subjects, the addition of $10 \mathrm{~cm} \mathrm{H}_{2} \mathrm{O}$ of PEEP to mechanical ventilation has been shown to reduce respiratory elastance and to improve oxygen exchange [57].

\section{Recruitment maneuver or alveolar recruitment strategy}

Bendixen and coll. [58], first demonstrated the physiological rationale of a lung recruitment maneuver (RM) to correct oxygenation impairment during anesthesia. Single manual ventilation up to $40 \mathrm{~cm}$ $\mathrm{H}_{2} \mathrm{O}$ was maintained for $15 \mathrm{~s}$ using the anesthesia bag while adjusting the expiratory valve. This pressure was equivalent to inflation up to vital capacity, and thus this maneuver was also called the vital capacity maneuver. More recently, it has been shown that this RM needs to be maintained for only 7-8 s in order to reexpand all previously collapsed lung tissue. Alternatively, atelectatic re-expansion can be performed either by stepwise increase of PEEP/inspiratory pressures (e.g., 0/10, $5 / 15,10 / 20,15 / 25 \mathrm{~cm} \mathrm{H}_{2} \mathrm{O}$ ) over 8 to 10 respiratory cycles (alveolar recruitment strategy [ARS]) or by applying continuous a positive airway pressure (CPAP) over 10-30 s [59].

To re-expand atelectatic areas, the lung opening pressure should be achieved by temporary elevation of Ptp while at end-expiration, Ptp should remain higher than the closing airway pressure. In other words, RM re-expands collapsed pulmonary acini and subsequent re-collapse is prevented by titration of external PEEP.

In obese patients undergoing laparoscopic bariatric surgery, intraoperative alveolar recruitment (vital capacity maneuver maintained for $8 \mathrm{~s}$ ) followed by $10 \mathrm{~cm} \mathrm{H}_{2} \mathrm{O}$ PEEP is more effective than ZEEP or PEEP of $5 \mathrm{~cm} \mathrm{H}$ O for prevention of postoperative lung atelectasis and is associated with better oxygenation, shorter stay in the postanesthesia care unit (PACU), and fewer pulmonary complications in the immediate postoperative period [60-62]. Application of PEEP and RM was not accompanied by a significant reduction in mean arterial pressure (MAP), even after pneumoperitoneum and reverse Trendelenbourg position.

During OLV, application of a RM to the dependent lung results in significant improvement in blood oxygenation and respiratory mechanics (reduced dead space, improved compliance) that is accompanied by transient and slight hemodynamic disturbances [63$65]$. 
At the end of surgery and before extubation, a single recruitment maneuver is not sufficient to produce sustained improvement in oxygenation [66]. Presumably, temporary increase in Ptp fails to reexpand large areas of atelectasis, air flow being diverted to the most compliant part of the lung and causing alveolar overdistension. Performing vital capacity at regular time interval might be necessary to reverse small volume of collapsed lung areas.

Specific contraindication to RM should be mentioned: hemodynamically unstable patients (hypovolemia), light levels of anesthesia (patient-ventilator dysynchrony), bronchospastic airways, pneumothorax, bronchopleural fistula and increased intracranial pressure.

\section{Tidal volume}

Based on experimental models of ALI/ARDS, the "open-lung" approach has been shown to minimize the bronchoalveolar strain using low $\mathrm{V}_{\mathrm{T}}$ while maintenance of the FRC and prevention or re-expansion of atelectasis is achieved with the application of PEEP and periodic RMs $[67,68]$. Ventilatory management with pressure and volume limited ventilation was found to reduce mortality in ten trials including 1,749 critically adults with ARDS (relative risk (RR) 0.84 ; 95\% CI 0.70 ) [69]. At similar PEEP levels, mechanical ventilation with lower $\mathrm{V}_{\mathrm{T}}(<8$ $\mathrm{ml} / \mathrm{kg}$ ) was associated with a $25 \%$ reduction in hospital mortality.

Prophylactic utilization of low VT may limit pulmonary and systemic inflammation (lesser release of IL- 8 and TNF in BALF and of plasma IL-6) in mechanically ventilated patients without preexisting lung injury [70,71]. In the ICU settings, such protective lung strategy have been associated with improved outcomes in terms of better survival, lesser barotrauma and shorter time on the ventilator in critically-ill patients [69].

Table 1 summarizes all RCTs including surgical patients that have questioned the impact of protective ventilatory settings (e.g., low $\mathrm{V}_{\mathrm{T}}$ with PEEP, RM) on markers of inflammation (systemic and pulmonary), oxygenation and postoperative pulmonary complications [72-85],

Not surprisingly, no difference was observed between traditional and protective ventilatory approaches in patients undergoing minor/ moderate surgical procedures, lasting less than $5 \mathrm{~h}$. In patients of higher surgical risk (major abdominal, thoracic and cardiac surgery), a protective ventilation" strategy $\left(\mathrm{V}_{\mathrm{T}} 4-6 \mathrm{ml} / \mathrm{kg}\right.$ PBW, PEEP with or without RM) was associated with a reduced expression of alveolar/ systemic inflammatory markers, reduced procoagulant activity in the bronchoalveolar fluid, better respiratory mechanical properties (dynamic compliance, airway resistance) and stable or improved oxygenation indices. In three of these RCTs, better clinical postoperative outcomes were reported in the group treated with the protective approach $[80,84,85]$. After major noncardiac surgery, Lee et al. [1] reported fewer pulmonary complications and shorter intubation times in patients ventilated postoperatively with small $\mathrm{V}_{\mathrm{T}}(6 \mathrm{vs} 12 \mathrm{ml} / \mathrm{kg})$ [80]. Michelet et al. [84] studied 52 patients undergoing oesophagectomy and observed lesser lung edema and better oxygenation index allowing earlier extubation among patients treated with low $\mathrm{V}_{\mathrm{T}}(5 \mathrm{ml} / \mathrm{kg})$ and 5 $\mathrm{cm} \mathrm{H}_{2} \mathrm{O}$ PEEP (compared with $10 \mathrm{ml} / \mathrm{kg} \mathrm{V}_{\mathrm{T}}$ and ZEEP). More recently, Yang et al. [85] compared two ventilatory strategies during OLV in 100 patients scheduled for lobectomy $\left(\mathrm{V}_{\mathrm{T}} 10 \mathrm{ml} / \mathrm{kg}\right.$, ZEEP and $\mathrm{FIO}_{2} 100 \%$ vs. $\mathrm{V}_{\mathrm{T}} 6 \mathrm{ml} / \mathrm{kg}, 5 \mathrm{~cm} \mathrm{H} \mathrm{H}_{2} \mathrm{O}$ PEEP and $\left.\mathrm{FIO}_{2} 0.5\right)$. The combined endpoint of pulmonary dysfunction $\left(\mathrm{PaO}_{2} / \mathrm{FIO}_{2}<300 \mathrm{mmHg}\right.$, lung atelectasis $)$ was significantly lower in the "protective" group than the control group ( $4 \%$ vs. $22 \%)$.
Although these preliminary results support the scientific concept of the "open lung" approach, we are awaiting the results of well designed RCTs with sufficient power and relevant clinical endpoints.

\section{$\mathrm{FIO}_{2}$}

In clinical anesthesia, hyperoxic ventilation $\left(\mathrm{FIO}_{2}>0.8\right)$ has been advocated for 2 reasons: 1 ) to prevent hypoxemia during anesthesia induction/emergence, by building up a large $\mathrm{O}_{2}$ store in the FRC and increasing the safety margin, 2) to promote the "killing" activity of PMN cells and prevent the occurrence of surgical site infection by increasing tissue $\mathrm{PO}_{2}$ during and shortly after surgery [86,87]. Absorption atelectasis and enhanced generation of $\mathrm{O}_{2}$ derived free radicals have been incriminated as potential drawbacks of high $\mathrm{FIO}_{2}$ levels.

Following anesthesia induction with $100 \% \mathrm{FIO}_{2}$, atelectatic areas may reach up to $5-10 \%$ of total lung volume whereas the amount of collapsed area is much less in those receiving less than $60 \% \mathrm{FIO}_{2}$.

Clinicians should be aware that, following pre-oxygenation at an $\mathrm{FIO}_{2}$ of 1.0, 7 min elapse before $\mathrm{SaO}_{2}$ decreases below $90 \%$; in contrast, at an $\mathrm{FIO}_{2}$ of 0.6 , the time delay before $\mathrm{O}_{2}$ desaturation is shorten to $3.5 \mathrm{~min}[88]$.

As a safety measure, pre-oxygenation with high $\mathrm{FIO}_{2}$ (80-100\%) is recommended to ensure sufficient time in case of difficult airway management. After airway control with a laryngeal mask or an endotracheal tube, an early RM should be performed and $\mathrm{FIO}_{2}$ should be reduced at a level sufficient to ensure optimal $\mathrm{O}_{2}$ delivery with $\mathrm{SaO}_{2}$ $>96 \%$ [89]. During anesthesia emergence, hyper-oxygenation is highly discussable as it promotes atelectasis formation [90].

\section{Normocapnia vs hypercapnia}

Most anesthetists tend to hyperventilate their surgical patients. In a cohort study including 3,421 patients undergoing colonic resection or gynaecologic interventions, the median etCO $\mathrm{CO}_{2}$ was $4.2 \mathrm{kPa}$ and higher etCO $\mathrm{C}_{2}$ was a predictor of reduced hospital length of stay lending support to the non-deleterious (or even favourable) effects of shortterm permissive hypercapnia [91].

The current recommendations for ventilatory settings are to target $\mathrm{SaO}_{2}>96 \%$ and end-tidal $\mathrm{CO}_{2}\left(\right.$ etCO $\left._{2}\right)$ within a range of $4.8-5.5 \mathrm{kPa}$, using a $\mathrm{V}_{\mathrm{T}}$ of $4-8 \mathrm{ml} / \mathrm{kg}$ PBW and pressure limited ventilation $(<30-35$ $\mathrm{cm} \mathrm{H}_{2} \mathrm{O}$ ).

Whenever possible, hypocapnia should be avoided given the risk of vasoconstriction of the cerebral vessels and the consequent neurocognitive dysfunction. On the other hand, hypercapnia can be better tolerated: although it may trigger the release of catecholamines causing an increase in oxygen consumption, it has been associated with improved $\mathrm{O}_{2}$ tissue delivery and with attenuation of key effectors of the inflammatory response and lung neutrophil infiltration [92,93]. Currently, clinical evidence supports the use of permissive hypercapnia, particularly in ALI/ARDS, status asthmaticus, and neonatal respiratory failure [94].

\section{Spontaneous ventilation}

Controlled mechanical ventilation is obviously indicated in the acute phase of lung illness to ensure adequate alveolar ventilation and to reduce work of breathing without causing further lung injury. In contrast, during the resolution phase of lung disease, spontaneous breathing during mechanical ventilation has been shown to improve gas exchange by redistribution of ventilation to dependent, juxtadiaphragmatic lung regions and thereby it promotes alveolar 
Citation: Licker MJ, Tschopp J, Diaper J (2012) Perioperative Lung Protective Strategies. J Pulmonar Respirat Med S2:002. doi:10.4172/2161-105X. S2-002

\begin{tabular}{|c|c|c|c|c|c|}
\hline Authors & $\begin{array}{l}\text { Publication } \\
\text { Year }\end{array}$ & $\mathrm{N}$ & Types of Surgery & Ventilation strategy & Effects of low $V_{T} V_{s}$ High $V_{T}$ \\
\hline \multicolumn{6}{|c|}{ Two Lung Ventilation } \\
\hline Wrigge et al. [72] & 2000 & 39 & $\begin{array}{l}\text { Visceral, orthopedic and } \\
\text { Vascular }\end{array}$ & $\begin{array}{l}5 \mathrm{ml} / \mathrm{kg} \text { ZEEP vs } 5 \mathrm{ml} / \mathrm{kg} 10 \mathrm{cmH}_{2} \mathrm{O} \text { PEEP } \\
\text { vs } 15 \mathrm{ml} / \mathrm{kg} 10 \text { PEEP }\end{array}$ & Similar plasma cytokine levels \\
\hline Wrigge et al. [73] & 2004 & 30 & Visceral & $\begin{array}{l}6 \mathrm{ml} / \mathrm{kg} 10 \mathrm{cmH}_{2} \mathrm{O} \text { PEEP vs. } 12-15 \mathrm{ml} / \\
\mathrm{kg} Z E E P\end{array}$ & $\begin{array}{l}\text { Similar time course of cytokines in tracheal } \\
\text { aspirate and plasma }\end{array}$ \\
\hline Choi et al. [74] & 2006 & 40 & Visceral & $6 \mathrm{ml} / \mathrm{kg} \mathrm{cmH} \mathrm{O}_{2} \mathrm{O}$ PEEP vs. $12 \mathrm{ml} / \mathrm{kg}$ ZEEP & $\begin{array}{l}\measuredangle \text { Thrombin anti-thrombin complex } \\
\nearrow \text { Activated Protein C in BALF } \\
\measuredangle \text { Thrombomoduline in BALF }\end{array}$ \\
\hline Wolthuis et al. [75] & 2008 & 40 & Visceral & $\begin{array}{l}6 \mathrm{ml} / \mathrm{kg} 10 \mathrm{cmH}_{2} \mathrm{O} \text { PEEP vs. } 12 \mathrm{ml} / \mathrm{kg} \\
\text { ZEEP }\end{array}$ & $\begin{array}{l}\text { Similar levels of TNF- } \alpha, \text { IL-1, MIP-1 in BALF } \\
\measuredangle I L-8 \text { in BALF } \\
\measuredangle \text { Myeloperoxidase and elastase om BALF } \\
\text { Similar levels of IL- } 6 \text { and IL-8 in plasma }\end{array}$ \\
\hline $\begin{array}{l}\text { Reis-Miranda et } \\
\text { al. [76] }\end{array}$ & 2005 & 62 & Cardiac & $\begin{array}{l}4-6 \mathrm{ml} / \mathrm{kg} 10 \mathrm{cmH}_{2} \mathrm{O} \text { PEEP+RM vs. 6-8 } \\
\mathrm{ml} / \mathrm{kg} 3 \mathrm{cmH}_{2} \mathrm{O} \text { PEEP }\end{array}$ & KIL-8, IL-10 in plasma \\
\hline Chaney et al. [77] & 2005 & 25 & Cardiac & $\begin{array}{l}6 \mathrm{ml} / \mathrm{kg} 10 \mathrm{cmH}_{2} \mathrm{O} \text { PEEP vs. } 12 \mathrm{ml} / \mathrm{kg} \\
\text { ZEEP }\end{array}$ & $\begin{array}{l}\lambda \mathrm{PaO}_{2} / \mathrm{FIO}_{2} \\
\measuredangle \mathrm{Static} \text { lung compliance }\end{array}$ \\
\hline Zupancich et al. [78] & 2005 & 40 & Post-cardiac & $\begin{array}{l}6 \mathrm{ml} / \mathrm{kg} 10 \mathrm{cmH}_{2} \mathrm{O} \text { PEEP vs. } 10-12 \mathrm{ml} / \mathrm{kg} \\
3 \mathrm{cmH}_{2} \mathrm{O} \text { PEEP }\end{array}$ & KIL-6 and IL-8 in BALF and plasma \\
\hline Koner et al. [79] & 2004 & 44 & Cardiac & $\begin{array}{l}6 \mathrm{ml} / \mathrm{kg} 5 \mathrm{cmH}_{2} \mathrm{O} \text { PEEP vs. } 10 \mathrm{ml} / \mathrm{kg} \\
\text { ZEEP vs } 10 \mathrm{ml} / \mathrm{kg} 10 \mathrm{cmH}_{2} \mathrm{O} \text { PEEP }\end{array}$ & $\begin{array}{l}\text { Similar plasma TNF- } \alpha \text { and IL-1 } \\
\text { Similar } \mathrm{PaO}_{2} / \mathrm{FIO}_{2}\end{array}$ \\
\hline Lee et al. [80] & 1990 & 103 & General & $6 \mathrm{ml} / \mathrm{kg}$ vs. $12 \mathrm{ml} / \mathrm{kg}$ & $\begin{array}{l}\measuredangle \text { Pulmonary infection } \\
\measuredangle \text { Duration of mechanical ventilation }\end{array}$ \\
\hline Wrigge et al. [81] & 2005 & 44 & Cardiac & $6 \mathrm{ml} / \mathrm{kg} 10$ PEEP vs. $12 \mathrm{ml} / \mathrm{kg}$ ZEEP & $\measuredangle T N F-\alpha$ in BALF similar plasma cytokine levels \\
\hline $\begin{array}{l}\text { Weingarten TN et } \\
\text { al. [82] }\end{array}$ & 2009 & 40 & Major open abdominal & $6 \mathrm{ml} / \mathrm{kg} 12$ PEEP vs. $10 \mathrm{ml} / \mathrm{kg}$ ZEEP & $\begin{array}{l}\nearrow \mathrm{PaO}_{2} / \mathrm{FIO}_{2}, \pi \text { Compliance, } \angle \text { Raw } \\
\measuredangle \mathrm{IL}-8, \measuredangle \mathrm{IL}-6 \text { in plasma (postop) } \\
\text { Similar length of hospital stay }\end{array}$ \\
\hline \multicolumn{6}{|l|}{ One- Lung Ventilation } \\
\hline Wrigge et al. [81] & 2004 & 32 & Lung resection & $\begin{array}{l}6 \mathrm{ml} / \mathrm{kg} 10 \mathrm{cmH}_{2} \mathrm{O} \text { PEEP vs. } 12-15 \mathrm{ml} / \\
\mathrm{kg} \text { ZEEP }\end{array}$ & $\begin{array}{l}\text { Similar time course of cytokines in tracheal } \\
\text { aspirate and plasma }\end{array}$ \\
\hline S chilling et al. [83] & 2005 & 32 & Lung resection & $5 \mathrm{ml} / \mathrm{kg}$ ZEEP vs. $10 \mathrm{ml} / \mathrm{kg}$ ZEEP & $\begin{array}{l}\angle \mathrm{TNF}-\alpha \text { and sICAM in BALF } \\
\text { Similar levels of albumin, elastase, IL-8, IL-10 }\end{array}$ \\
\hline Michelet et al. [84] & 2006 & 52 & Oesophagectomy & $5 \mathrm{ml} / \mathrm{kg} 5 \mathrm{cmH}_{2} \mathrm{O}$ PEEP vs. $9 \mathrm{ml} / \mathrm{kg}$ ZEEP & $\begin{array}{l}K \mathrm{IL}-1, \mathrm{IL}-6, \mathrm{IL}-8 \text { in plasma } \\
7 \mathrm{PaO}_{2} / \mathrm{FIO} \mathrm{I}_{2} \text { and } \measuredangle \text { lung water content } \\
\measuredangle \mathrm{Duration}_{\text {of }} \text { mechanical ventilation }\end{array}$ \\
\hline Yang $\mathrm{m}$ et al. [85] & 2011 & 100 & Lung resection & $\begin{array}{l}6 \mathrm{ml} / \mathrm{kg} 5 \mathrm{cmH}_{2} \mathrm{O} \text { PEEP, } \mathrm{FIO}_{2} 0.5+\mathrm{RM} \text { vs. } \\
10 \mathrm{ml} / \mathrm{kg} \mathrm{ZEEP}, \mathrm{FIO}_{2} 1.0\end{array}$ & $\begin{array}{l}\angle \text { Postoperaive pulmonary dysfunction }\left(\mathrm{PaO}_{2} / \mathrm{FIO}_{2}\right. \\
<300 \mathrm{mmHg} \text {, atelectasis })\end{array}$ \\
\hline
\end{tabular}

BALF, bronchoalveolar lavage fluid; RM, recruitment maneuver; IL, Interleukin; PEEP, positive end expiratory pressure; ZEEP, zero end expiratory pressure; TNF, tumor necrosis factor; IL-x; $\mathrm{PaO}_{2} / \mathrm{FIO}_{2}$, ratio of arterial oxygen pressure to fractional inspiratory oxygen pressure

Table 1: Randomized controlled trials assessing the effects of different modes of ventilation.

recruitment. Moreover, during assisted ventilation, cardiovascular and sedative drug support can be reduced as a result of improved venous return and better patient-ventilator synchronization [95].

For various surgical procedures involving the limbs and the thoraco-abdominal wall, regional anesthetic blockade (e.g. perineural infiltration or neuraxial block) is sufficient to provide patient comfort. For intra-thoracic and intra-abdominal interventions, complete muscles paralysis is not always mandatory through the whole procedure; spontaneous ventilation can be maintained under light-tomoderate levels of sedation combined with systemic administration of short-acting opiate [96].

During anesthesia emergence, pressure support ventilation (PSV) may provide lower work of breathing and improved comfort for patients with increased and variable respiratory demand. In addition, with assist mode of ventilation, recruitment of dependent collapsed lung areas and redistribution of pulmonary blood flow towards nondependent zone result in improved oxygenation and restoration of the FRC $[97,98]$.

Postoperatively, two types of noninvasive ventilation (NIV) are commonly used: continuous positive airway pressure (CPAP) and noninvasive positive pressure ventilation (NPPV) which delivers two levels of positive pressure (pressure support ventilation + positive endexpiratory pressure). There are two main indications for NIV: first, "prophylactic" application in high-risk patients (elderly, obese, COPD, heart failure) in order to prevent postoperative acute respiratory failure from developing and, second, "curative" application of NIV once ARF has occurred to avoid endotracheal intubation while alleviating respiratory insufficiency.

Although there is some evidence of the effectiveness of NIV in preventing post-extubation ERF, the benefits in the treatment of ongoing ARF are still debatable [99].

When applying NIV in surgical patients, clinicians should also considered the hemodynamic effects of positive pressure to the cardiovascular system, which can be favorable on the impaired left heart and deleterious on the diseased right heart [100].

\section{Alternate Perioperative Lung Protective Strategies}

Newer technological modalities including extracorporeal membrane oxygenation (ECMO) and pumpless extracorporeal lung assist (PECLA) are being increasingly introduced in critical care settings as rescue therapies in acute respiratory failure unresponsive to conservative measures. As arterio-venous or veno-venous ECMO or PECLA provide gas exchange, the exposure time of the lungs to high 
stress and/or strain can be minimized by switching the ventilatory settings to a protective regimen (low $\mathrm{V}_{\mathrm{T}}$ with PEEP) enabling the lung to rest and to heal [101].

Prehospital use of statin (particularly with aspirin) has been shown to confer lung protection in various experimental models of ALI as well as in septic patients $[102,103]$. Likewise, angiotensin-converting enzyme inhibitors such as enalapril have emerged as strong candidates in lung protection given their ability to block the LPS-induced antiinflammatory effects [104]. Finally, preliminary clinical data suggest that the administration of inhaled beta 2-adrenergic agonists may accelerate the resorption of lung edema by enhancing active sodium and water transport in alveolar pneumocytes [105].

Although restrictive fluid regimen has been advocated, - particularly in thoracic surgery -, clinically "silent" hypovolemic state and the need for vasopressors have been associated with the development of postoperative acute kidney injury [106]. Nowadays, new hemodynamic monitoring tools enable clinicians to titrate the amount of fluid infused to achieve adequate tissue $\mathrm{O}_{2}$ delivery while avoiding excess in intrathoracic blood volume (LiDCO system) or extra vascular lung water (PiCCO system). Monitoring stroke volume and/or respiratoryinduced variation in pulse pressure variation allows a goal-directed fluid and cardiovascular drug therapy that may contribute to avoid over hydration while improving gas exchange and tissue oxygen delivery [107].

\section{Conclusions and Practice Points}

Implementation of a bundle of scientifically based perioperative interventions represents an integral component of quality control and improved clinical care.

The traditional intraoperative ventilatory settings $\left(\mathrm{V}_{\mathrm{T}}>10 \mathrm{ml} /\right.$ kg PBW) can be harmful even in patients with healthy lungs. In the operating theatre, our task is provide safe anesthesia and to ensure satisfactory oxygen delivery while minimizing the deleterious effects of surgical trauma and avoiding iatrogenic complications (e.g. fluid over hydration, airway trauma, VILI, atelectasis, bronchoaspiration, toxic drug effects, hyperoxia/hypoxia).

To achieve these goals, the following key items should be considered:

- Pre-oxygenate with a high $\mathrm{FIO}_{2}(>80 \%)$ before anesthesia induction, allowing a large margin of safety in case of difficult airway management. During manual ventilation before tracheal intubation, a small positive pressure can be maintained throughout the whole respiratory cycle (inspiratory pressure less than $25 \mathrm{~cm} \mathrm{H}_{2} \mathrm{O}$ with 4-6 $\mathrm{cm} \mathrm{H}_{2} \mathrm{O}$ PEEP). In morbidly obese patients and in those requiring a rapid sequence induction, $\mathrm{CPAP}$ has been advocated during preoxygenation.

- After securing the airways (with a laryngeal mask, an ET or a double-lumen tube):

- a recruitment manoeuvre is performed (inspiratory $\mathrm{P}$ of 40 $\mathrm{cm} \mathrm{H}_{2} \mathrm{O}$ for $8-10 \mathrm{~s}$ )

○ $\quad \mathrm{V}_{\mathrm{T}}$ of $6-8 \mathrm{ml} / \mathrm{kg}$ (of predicted body weight) is selected with limitation of the $\mathrm{Ppl}<20 \mathrm{~cm} \mathrm{H}_{2} \mathrm{O}\left(<30 \mathrm{~cm} \mathrm{H}_{2} \mathrm{O}\right.$ in damaged lungs or during OLV)

- PEEP is set empirically $\left(4-6 \mathrm{~cm} \mathrm{H}_{2} \mathrm{O}, 10 \mathrm{~cm} \mathrm{H} 2=\right.$ in morbidly obese) or titrated using the PV loops or $\mathrm{CO}_{2}$ curves
- $\mathrm{FIO}_{2}$ can be reduced to levels sufficient to keep $\mathrm{SaO}_{2}>96 \%$ $\left(\mathrm{FIO}_{2}<60 \%\right)$

- The use of volatile anesthetic should be considered in patients with bronchospastic disease and may potentially confer additional protection to the lungs and other organs.

Pressure or Volume controlled ventilation might be used in paralyzed patients. Apply assisted mechanical ventilation whenever possible and particularly at the end of surgery before tracheal extubation: patient's respiratory efforts are triggered and assisted by the ventilator.

- Before extubation, a gentle recruitment maneuver is recommended; hyper oxygenation with $100 \% \mathrm{FIO}_{2}$ is not mandatory ( $50 \%$ to $70 \%$ is enough).

- In the postoperative period, voluntary deep breathing and early mobilization should be encouraged and will be facilitated if optimal analgesic techniques are provided without undue sedation and while cardiovascular homeostasis is maintained. In high risk patients, NIV techniques may reduce the risk of postoperative acute respiratory failure and the need of reintubation.

- Use of minimally invasive hemodynamic monitors for is useful for goal-directed fluid loading and titration of cardiovascular drugs. Monitoring the depth of anesthesia, cardiac output or using dynamic indices should be considered in major surgery or high-risk patients.

\section{References}

1. Fleischmann KE, Goldman L, Young B, Lee TH (2003) Association between cardiac and noncardiac complications in patients undergoing noncardiac surgery: outcomes and effects on length of stay. Am J Med 115: 515-520.

2. Smetana GW, Lawrence VA, Cornell JE (2006) Preoperative pulmonary risk stratification for noncardiothoracic surgery: systematic review for the American College of Physicians. Ann Intern Med 144: 581-595.

3. Schussler O, Alifano M, Dermine H, Strano S, Casetta A, et al. (2006) Postoperative pneumonia after major lung resection. Am J Respir Crit Care Med 173: 1161-1169.

4. Licker MJ, Widikker I, Robert J, Frey JG, Spiliopoulos A, et al. (2006) Operative mortality and respiratory complications after lung resection for cancer: impact of chronic obstructive pulmonary disease and time trends. Ann Thorac Surg 81: $1830-1837$

5. Boffa DJ, Allen MS, Grab JD, Gaissert HA, Harpole DH, et al. (2008) Data from The Society of Thoracic Surgeons General Thoracic Surgery database: the surgical management of primary lung tumors. J Thorac Cardiovasc Surg 135: $247-254$

6. Memtsoudis SG, Besculides MC, Zellos L, Patil N, Rogers SO (2006) Trends in lung surgery: United States 1988 to 2002. Chest 130: 1462-1470.

7. Fisher BW, Majumdar SR, McAlister FA (2002) Predicting pulmonary complications after nonthoracic surgery: a systematic review of blinded studies. Am J Med 112: 219-225

8. Licker M, Schnyder JM, Frey JG, Diaper J, Cartier V, et al. (2011) Impact of aerobic exercice capacity and procedure-related factors in lung cancer surgery. Eur Respir J 37: 1189-1198.

9. Dindo D, Demartines N, Clavien PA (2004) Classification of surgica complications: a new proposal with evaluation in a cohort of 6336 patients and results of a survey. Ann Surg 240: 205-213.

10. Hedenstierna G, Rothen HU (2000) Atelectasis formation during anesthesia: causes and measures to prevent it. J Clin Monit Comput 16: 329-335.

11. Rothen HU, Sporre B, Engberg G, Wegenius G, Hedenstierna G (1998) Airway closure, atelectasis and gas exchange during general anaesthesia. $\mathrm{Br}$ J Anaesth 81: 681-686.

12. Rothen HU, Sporre B, Engberg G, Wegenius G, Hogman M, et al. (1995) 
Influence of gas composition on recurrence of atelectasis after a reexpansion maneuver during general anesthesia. Anesthesiology 82: 832-842.

13. Hedenstierna G, Edmark L (2005) The effects of anesthesia and muscle paralysis on the respiratory system. Intensive Care Med 31: 1327-1335

14. D'Angelo E, Koutsoukou A, Della Valle P, Gentile G, Pecchiari M (2008) Cytokine release, small airway injury, and parenchymal damage during mechanical ventilation in normal open-chest rats. J Appl Physiol 104: 41-49.

15. Demoule A, Decailliot F, Jonson B, Christov C, Maitre B, et al. (2006) Relationship between pressure-volume curve and markers for collagen turnover in early acute respiratory distress syndrome. Intensive Care Med 32: 413420

16. Pavone LA, Albert S, Carney D, Gatto LA, Halter JM, et al. (2007) Injurious mechanical ventilation in the normal lung causes a progressive pathologic change in dynamic alveolar mechanics. Crit Care 11: R64.

17. Musch G, Venegas JG, Bellani G, Winkler T, Schroeder T, et al. (2007) Regional gas exchange and cellular metabolic activity in ventilator-induced lung injury. Anesthesiology 106: 723-735.

18. Perl M, Chung CS, Perl U, Biffl WL, Cioffi WG, et al. (2007) Beneficial versus detrimental effects of neutrophils are determined by the nature of the insult. $J$ Am Coll Surg 204: 840-852.

19. Perl M, Chung CS, Perl U, Lomas-Neira J, de Paepe M, et al. (2007) Fasinduced pulmonary apoptosis and inflammation during indirect acute lung injury. Am J Respir Crit Care Med 176: 591-601.

20. Tasaka S, Amaya F, Hashimoto S, Ishizaka A (2008) Roles of oxidants and redox signaling in the pathogenesis of acute respiratory distress syndrome. Antioxid Redox Signal 10: 739-753.

21. Sinclair SE, Altemeier WA, Matute-Bello G, Chi EY (2004) Augmented lung injury due to interaction between hyperoxia and mechanical ventilation. Crit Care Med 32: 2496-2501.

22. Funakoshi T, Ishibe Y, Okazaki N, Miura K, Liu R, et al. (2004) Effect of reexpansion after short-period lung collapse on pulmonary capillary permeability and pro-inflammatory cytokine gene expression in isolated rabbit lungs. $\mathrm{Br} \mathrm{J}$ Anaesth 92: 558-563.

23. Tsuchida S, Engelberts D, Peltekova V, Hopkins N, Frndova H, et al. (2006) Atelectasis causes alveolar injury in nonatelectatic lung regions. Am J Respir Crit Care Med 174: 279-289.

24. Pavone L, Albert S, DiRocco J, Gatto L, Nieman G (2007) Alveolar instability caused by mechanical ventilation initially damages the nondependent normal lung. Crit Care 11: R104

25. Dreyfuss D, Soler P, Basset G, Saumon G (1988) High inflation pressure pulmonary edema. Respective effects of high airway pressure, high tidal volume, and positive end-expiratory pressure. Am Rev Respir Dis 137: 11591164.

26. Frank JA, Parsons PE, Matthay MA (2006) Pathogenetic significance of biological markers of ventilator-associated lung injury in experimental and clinical studies. Chest 130: 1906-1914.

27. Licker M, de Perrot M, Spiliopoulos A, Robert J, Diaper J, et al. (2003) Risk factors for acute lung injury after thoracic surgery for lung cancer. Anesth Analg 97: 1558-1565

28. Fernandez-Perez ER, Keegan MT, Brown DR, Hubmayr RD, Gajic O (2006) Intraoperative tidal volume as a risk factor for respiratory failure after pneumonectomy. Anesthesiology 105: 14-18.

29. Fernández-Pérez ER, Sprung J, Afessa B, Warner DO, Vachon CM, et al (2009) Intraoperative ventilator settings and acute lung injury after elective surgery: a nested case control study. Thorax 64: 121-127.

30. Kilpatrick B, Slinger $P$ (2010) Lung protective strategies in anaesthesia. Br J Anaesth 105: 108-116.

31. Meyer NJ, Garcia JG (2007) Wading into the genomic pool to unravel acute lung injury genetics. Proc Am Thorac Soc 4: 69-76.

32. Marzec JM, Christie JD, Reddy SP, Jedlicka AE, Vuong $\mathrm{H}$, et al. (2007) Functional polymorphisms in the transcription factor NRF2 in humans increase the risk of acute lung injury. FASEB J 21: 2237-2246.

33. Lee JM, Lo AC, Yang SY, Tsau HS, Chen RJ, et al. (2005) Association of angiotensin-converting enzyme insertion/deletion polymorphism with serum level and development of pulmonary complications following esophagectomy. Ann Surg 241: 659-665.
34. Pruszkowski O, Dalibon N, Moutafis M, Jugan E, Law-Koune JD, et al. (2007) Effects of propofol vs sevoflurane on arterial oxygenation during one-lung ventilation. $\mathrm{Br} \mathrm{J}$ Anaesth 98: 539-544.

35. Reutershan J, Chang D, Hayes JK, Ley K (2006) Protective effects of isoflurane pretreatment in endotoxin-induced lung injury. Anesthesiology 104: 511-517.

36. Voigtsberger S, Lachmann RA, Leutert AC, Schläpfer M, Booy $C$, et al (2009) Sevoflurane ameliorates gas exchange and attenuates lung damage in experimental lipopolysaccharide-induced lung injury. Anesthesiology 111 1238-1248.

37. Boost KA, Flondor M, Hofstetter C, Platacis I, Stegewerth K, et al. (2007) The beta-adrenoceptor antagonist propranolol counteracts anti-inflammatory effects of isoflurane in rat endotoxemia. Acta Anaesthesiol Scand 51: 900-908.

38. Schilling T, Kozian A, Kretzschmar M, Huth C, Welte T, et al. (2007) Effects of propofol and desflurane anaesthesia on the alveolar inflammatory response to one-lung ventilation. $\mathrm{Br} \mathrm{J}$ Anaesth 99: 368-375

39. De Conno E, Steurer MP, Wittlinger M, Zalunardo MP, Weder W, et al. (2009) Anesthetic-induced improvement of the inflammatory response to one-lung ventilation. Anesthesiology 110: 1316-1326

40. Campbell RS, Davis BR (2002) Pressure-controlled versus volume-controlled ventilation: does it matter? Respir Care 47: 416-424

41. Jo YY, Kim JY, Kwak YL, Kim YB, Kwak HJ (2011) The Effect of Pressurecontrolled Ventilation on Pulmonary Mechanics in the Prone Position During Posterior Lumbar Spine Surgery: A Comparison With Volume controlled Ventilation. J Neurosurg Anesthesiol 24: 14-18.

42. Prella M, Feihl F, Domenighetti G (2002) Effects of short-term pressurecontrolled ventilation on gas exchange, airway pressures, and gas distribution in patients with acute lung injury/ARDS: comparison with volume-controlled ventilation. Chest 122: 1382-1388.

43. Antonaglia V, Lucangelo U, Ristagno G, Tantillo S, Ferluga M, et al. (2010) Gas distribution in a two-compartment model during volume or pressure ventilation: role of elastic elements. Respir Physiol Neurobiol 171: 225-231.

44. Edibam C, Rutten AJ, Collins DV, Bersten AD (2003) Effect of inspiratory flow pattern and inspiratory to expiratory ratio on nonlinear elastic behavior in patients with acute lung injury. Am J Respir Crit Care Med 167: 702-707.

45. 45.Wongviriyawong C, Winkler T, Harris RS, Venegas JG (2010) Dynamics of tidal volume and ventilation heterogeneity under pressure-controlled ventilation during bronchoconstriction: a simulation study. J Appl Physiol 109: 1211-1218.

46. Tuğrul M, Camci E, Karadeniz H, Sentürk M, Pembeci K, et al. (1997) Comparison of volume controlled with pressure controlled ventilation during one-lung anaesthesia. $\mathrm{Br} \mathrm{J}$ Anaesth 79: 306-310.

47. Sentürk NM, Dilek A, Camci E, Sentürk E, Orhan M, et al. (2005) Effects of positive end-expiratory pressure on ventilatory and oxygenation parameters during pressure-controlled one-lung ventilation. J Cardiothorac Vasc Anesth 19: $71-75$.

48. Unzueta MC, Casas JI, Moral MV (2007) Pressure-controlled versus volumecontrolled ventilation during one-lung ventilation for thoracic surgery. Anesth Analg 104: 1029-1033.

49. Montes FR, Pardo DF, Charrís H, Tellez LJ, Garzón JC, et al. (2010) Comparison of two protective lung ventilatory regimes on oxygenation during one-lung ventilation: a randomized controlled trial. J Cardiothorac Surg 5: 99.

50. Heimberg C, Winterhalter M, Strüber M, Piepenbrock S, Bund M (2006) Pressure-controlled versus volume-controlled one-lung ventilation for MIDCAB Thorac Cardiovasc Surg 54: 516-520.

51. Pardos PC, Garutti I, Piñeiro P, Olmedilla L, de la Gala F (2009) Effects of ventilatory mode during one-lung ventilation on intraoperative and postoperative arterial oxygenation in thoracic surgery. J Cardiothorac Vasc Anesth 23: 770 774.

52. Rozé H, Lafargue $M$, Batoz H, Picat $M Q$, Perez $P$, et al. (2010) Pressurecontrolled ventilation and intrabronchial pressure during one-lung ventilation. Br J Anaesth 105: 377-381

53. Rothen HU, Sporre B, Engberg G, Wegenius G, Reber A, et al. (1995) Prevention of atelectasis during general anaesthesia. Lancet 345: 1387-1391.

54. Caramez MP, Kacmarek RM, Helmy M, Miyoshi E, Malhotra A, et al. (2009) A comparison of methods to identify open-lung PEEP. Intensive Care Med 35 740-747. 
55. Böhm SH, Maisch S, von Sandersleben A, Thamm O, Passoni I, et al. (2009) The effects of lung recruitment on the Phase III slope of volumetric capnography in morbidly obese patients. Anesth Analg 109: 151-159.

56. Imberger G, Mcllroy D, Pace NL, Wetterslev J, Brok J, et al. (2010) Positive end-expiratory pressure (PEEP) during anaesthesia for the prevention of mortality and postoperative pulmonary complications. Cochrane Database Syst Rev 9: CD007922.

57. Pelosi P, Ravagnan I, Giurati G, Panigada M, Bottino N, et al. (1999) Positive end-expiratory pressure improves respiratory function in obese but not in normal subjects during anesthesia and paralysis. Anesthesiology 91: 12211231.

58. Bendixen HH, Hedley-Whyte J, Laber MB (1963) Impaired oxygenation in surgical aptients during general anesthesia with controlled ventilation-A concept of atelectasis N Engl J Med 269: 991-996.

59. Tusman G, Böhm SH (2010) Prevention and reversal of lung collapse during the intra-operative period. Best Pract Res Clin Anaesthesiol 24: 183-197.

60. Futier E, Constantin JM, Pelosi P, Chanques G, Kwiatkoskwi F, et al. (2010) Intraoperative recruitment maneuver reverses detrimental pneumoperitoneuminduced respiratory effects in healthy weight and obese patients undergoing laparoscopy. Anesthesiology 113: 1310-1319.

61. Whalen FX, Gajic O, Thompson GB, Kendrick ML, Que FL, et al. (2006) The effects of the alveolar recruitment maneuver and positive end-expiratory pressure on arterial oxygenation during laparoscopic bariatric surgery. Anesth Analg 102: 298-305.

62. Talab HF, Zabani IA, Abdelrahman HS, Bukhari WL, Mamoun I, et al. (2009) Intraoperative ventilatory strategies for prevention of pulmonary atelectasis in obese patients undergoing laparoscopic bariatric surgery. Anesth Analg 109 : 1511-1516.

63. Cinnella G, Grasso S, Natale C, Sollitto F, Cacciapaglia M, et al. (2008) Physiological effects of a lung-recruiting strategy applied during one-lung ventilation. Acta Anaesthesiol Scand 52: 766-775.

64. Garutti I, Martinez G, Cruz P, Piñeiro P, Olmedilla L, et al. (2009) The impact of lung recruitment on hemodynamics during one-lung ventilation. J Cardiothorac Vasc Anesth 23: 506-508.

65. Tusman G, Böhm SH, Sipmann FS, Maisch S (2004) Lung recruitment improves the efficiency of ventilation and gas exchange during one-lung ventilation anesthesia. Anesth Analg 98: 1604-1609.

66. Lumb AB, Greenhill SJ, Simpson MP, Stewart J (2010) Lung recruitment and positive airway pressure before extubation does not improve oxygenation in the post-anaesthesia care unit: a randomized clinical trial. Br J Anaesth 104: 643-647.

67. Lachmann B (1992) Open up the lung and keep the lung open. Intensive Care Med 18: 319-321.

68. Verbrugge SJ, Lachmann B, Kesecioglu J (2007) Lung protective ventilatory strategies in acute lung injury and acute respiratory distress syndrome: from experimental findings to clinical application. Clin Physiol Funct Imaging 27: 6790.

69. Burns KE, Adhikari NK, Slutsky AS, Guyatt GH, Villar J, et al. (2011) Pressure and volume limited ventilation for the ventilatory management of patients with acute lung injury: a systematic review and meta-analysis. PLoS One 6: e14623.

70. Determann RM, Royakkers A, Wolthuis EK, Vlaar AP, Choi G, et al. (2010) Ventilation with lower tidal volumes as compared with conventional tidal volumes for patients without acute lung injury: a preventive randomized controlled trial. Crit Care 14: R1

71. Pinheiro de Oliveira R, Hetzel MP, dos Anjos Silva M, Dallegrave D, Friedman G (2010) Mechanical ventilation with high tidal volume induces inflammation in patients without lung disease. Crit Care 14: R39.

72. Wrigge H, Zinserling J, Stuber F, von Spiegel T, Hering R, et al. (2000) Effects of mechanical ventilation on release of cytokines into systemic circulation in patients with normal pulmonary function. Anesthesiology 93: 1413-1417.

73. Wrigge $\mathrm{H}$, Uhlig $\mathrm{U}$, Zinserling J, Behrends-Callsen $\mathrm{E}$, Ottersbach $\mathrm{G}$, et al (2004) The effects of different ventilatory settings on pulmonary and systemic inflammatory responses during major surgery. Anesth Analg 98: 775-781.

74. Choi G, Wolthuis EK, Bresser P, Levi M, van der Poll T, et al. (2006) Mechanical ventilation with lower tidal volumes and positive end-expiratory pressure prevents alveolar coagulation in patients without lung injury. Anesthesiology 105: 689-695

75. Wolthuis EK, Choi G, Dessing MC, Bresser P, Lutter R, et al. (2008) Mechanical ventilation with lower tidal volumes and positive end-expiratory pressure prevents pulmonary inflammation in patients without preexisting lung injury. Anesthesiology 108: 46-54

76. Reis Miranda D, Gommers D, Struijs A, Dekker R, Mekel J, et al. (2005) Ventilation according to the open lung concept attenuates pulmonary inflammatory response in cardiac surgery. Eur J Cardiothorac Surg 28: 889895

77. Chaney MA, Nikolov MP, Blakeman BP, Bakhos M (2000) Protective ventilation attenuates postoperative pulmonary dysfunction in patients undergoing cardiopulmonary bypass. J Cardiothorac Vasc Anesth 14: 514-518.

78. Zupancich E, Paparella D, Turani F, Munch C, Rossi A, et al. (2005) Mechanical ventilation affects inflammatory mediators in patients undergoing cardiopulmonary bypass for cardiac surgery: a randomized clinical trial. Thorac Cardiovasc Surg 130: 378-383.

79. Koner O, Celebi S, Balci H, Cetin G, Karaoglu K, et al. (2004) Effects of protective and conventional mechanical ventilation on pulmonary function and systemic cytokine release after cardiopulmonary bypass. Intensive Care Med 30: $620-626$.

80. Lee PC, Helsmoortel CM, Cohn SM, Fink MP (1990) Are low tidal volumes safe? Chest 97: 430-434

81. Wrigge H, Uhlig U, Baumgarten G, Menzenbach J, Zinserling J, et al. (2005) Mechanical ventilation strategies and inflammatory responses to cardiac surgery: a prospective randomized clinical trial. Intensive Care Med 31: 13791387

82. Weingarten TN, Whalen FX, Warner DO, Gajic O, Schears GJ, et al. (2010) Comparison of two ventilatory strategies in elderly patients undergoing major abdominal surgery. Br J Anaesth 104: 16-22.

83. Schilling T, Kozian A, Huth C, Buhling F, Kretzschmar M, et al. (2005) The pulmonary immune effects of mechanical ventilation in patients undergoing thoracic surgery. Anesth Analg 101: 957-965.

84. Michelet P, D'Journo XB, Roch A, Doddoli C, Marin V, et al. (2006) Protective ventilation influences systemic inflammation after esophagectomy: a randomized controlled study. Anesthesiology 105: 911-919.

85. Yang M, Ahn HJ, Kim K, Kim JA, Yi CA, et al. (2011) Does a Protective Ventilation Strategy Reduce the Risk of Pulmonary Complications after Lung Cancer Surgery?: a Randomized Controlled Trial. Chest 139: 530-537.

86. Edmark L, Auner U, Enlund M, Ostberg E, Hedenstierna G (2011) Oxygen concentration and characteristics of progressive atelectasis formation during anaesthesia. Acta Anaesthesiol Scand 55: 75-81.

87. Belda FJ, Aguilera L, García de la Asunción J, Alberti J, Vicente R, et al. (2005) Supplemental perioperative oxygen and the risk of surgical wound infection: a randomized controlled trial. JAMA 294: 2035-2042.

88. Edmark L, Kostova-Aherdan K, Enlund M, Hedenstierna G (2003) Optima oxygen concentration during induction of general anesthesia. Anesthesiology 98: 28-33

89. Rothen HU, Sporre B, Engberg G, Wegenius G, Högman M, et al. (1995 Influence of gas composition on recurrence of atelectasis after a reexpansion maneuver during general anesthesia. Anesthesiology 82: 832-842.

90. Benoît Z, Wicky S, Fischer JF, Frascarolo P, Chapuis C, et al. (2002) The effect of increased $\mathrm{FIO}(2)$ before tracheal extubation on postoperative atelectasis. Anesth Analg 95: 1777-1781.

91. Wax DB, Lin HM, Hossain S, Porter SB (2010) Intraoperative carbon dioxide management and outcomes. Eur J Anaesthesiol. 27: 819-823.

92. Low JM, Gin T, Lee TW, Fung K (1993) Effect of respiratory acidosis and alkalosis on plasma catecholamine concentrations in anaesthetized man. Clin Sci 84: 69-72.

93. Fleischmann E, Herbst F, Kugener A, Kabon B, Niedermayr M, et al. (2006) Mild hypercapnia increases subcutaneous and colonic oxygen tension in patients given $80 \%$ inspired oxygen during abdominal surgery. Anesthesiology 104: 944-949.

94. Curley G, Hayes M, Laffey JG (2011) Can permissive hypercapnia modulate the severity of sepsis-induced ALI/ARDS? Crit Care 15: 212 
95. Putensen C, Muders T, Varelmann D, Wrigge H (2006) The impact of spontaneous breathing during mechanical ventilation. Curr Opin Crit Care 12: 13-18.

96. Tschopp JM, Purek L, Frey JG, Schnyder JM, Diaper J, et al. (2011) Titrated sedation with propofol for medical thoracoscopy: a feasibility and safety study. Respiration 82: 451-457.

97. Carvalho AR, Spieth PM, Pelosi P, Beda A, Lopes AJ, et al. (2009) Pressure support ventilation and biphasic positive airway pressure improve oxygenation by redistribution of pulmonary blood flow. Anesth Analg 109: 856-865.

98. Zoremba M, Kalmus G, Dette F, Kuhn C, Wulf H (2010) Effect of intra-operative pressure support vs pressure controlled ventilation on oxygenation and lung function in moderately obese adults. Anaesthesia 65: 124-129.

99. Guarracino F, Ambrosino N (2011) Non-invasive ventilation in cardio-surgical patients. Minerva Anestesiol 77: 734-741.

100. Chiumello D, Chevallard G, Gregoretti C (2011) Non-invasive ventilation in postoperative patients: a systematic review. Intensive Care Med 37: 918-929.

101.Brodie D, Bacchetta M (2011) Extracorporeal membrane oxygenation for ARDS in adults. N Engl J Med 365: 1905-1914.
02. O'Neal HR, Koyama T, Koehler EA, Siew E, Curtis BR, et al. (2011) Prehospital statin and aspirin use and the prevalence of severe sepsis and acute lung injury/acute respiratory distress syndrome. Crit Care Med 39: 1343-1350.

103. Altintas ND, Atilla P, Iskit AB, Topeli A (2011) Long-term simvastatin attenuates lung injury and oxidative stress in murine acute lung injury models induced by oleic Acid and endotoxin. Respir Care 56: 1156-1163.

104. Hagiwara S, Iwasaka H, Matumoto S, Hidaka S, Noguchi T (2009) Effects of an angiotensin-converting enzyme inhibitor on the inflammatory response in in vivo and in vitro models. Crit Care Med 37: 626-633.

105. Licker M, Tschopp JM, Robert J, Frey JG, Diaper J, et al. (2008) Aerosolized salbutamol accelerates the resolution of pulmonary edema after lung resection. Chest 133: $845-852$

106. Licker M, Cartier V, Robert J, Diaper J, Villiger Y, et al. (2011) Risk factors of acute kidney injury according to RIFLE criteria after lung cancer surgery. Ann Thorac Surg 91: 844-850.

107.Diaper J, Ellenberger C, Villiger Y, Robert J, Tschopp JM, et al. (2008) Transoesophageal Doppler monitoring for fluid and hemodynamic treatment during lung surgery. J Clin Monit Comput 22: 367-374.
This article was originally published in a special issue, Acute Lung Injury handled by Editor(s). Dr. Yuanlin Song, Fudan University, China 